\title{
El nuevo Hollywood y la posmodernidad: entre la subversión y el neoconservadurismo
}

\section{Katixa Agirre ${ }^{1}$}

Recibido: 2013-10-15

Envío a pares: 2013-10-25
Aprobado por pares: 2014-01-12

Aceptado: 2014-01-13

DOI: 10.5294/pacla.2014.17.3.4

Para citar este artículo / To reference this article / Para citar este artigo

Agirre, K. Septiembre de 2014. El nuevo Hollywood y la posmodernidad: entre la subversión y el neoconservadurismo. Palabra Clave 17 (3), 645-671. DOI: 10.5294/ pacla.2014.17.3.4

\section{Resumen}

El artículo examina el fenómeno del cine posmoderno -su contexto y características- y su influencia en el nuevo Hollywood. Ofreciendo numerosos ejemplos se propone una reflexión sobre el potencial crítico y subversivo de éste, para concluir que, por mucho que el cine posmoderno ofrezca herramientas para la crítica política -particularmente la parodia- los films hollywoodiense se alinean típicamente con ideas neoconservadoras o resultan acríticos.

\section{Palabras clave}

Cine, Hollywood, posmodernidad, parodia, crítica (Fuente: Tesauro de la Unesco).

1 Universidad del País Vasco UPV/EHU, España. katixa.agirre@ehu.es 


\section{New Hollywood and Post-modernity: Between Subversion and Neo- conservatism}

\section{Abstract}

The phenomenon of postmodern cinema-its context and characteristicsand its influence in new Hollywood is examined in this article. Through numerous examples, it reflects on the critical and subversive potential of postmodern cinema and concludes that, however much it provides tools for political criticism - particularly parody - Hollywood films typically are aligned with neo-conservative ideas or are uncritical.

\section{Keywords}

Films, Hollywood, postmodernism, parody, critique (Source: UNESCO Thesaurus). 


\section{A Nova Hollywood e a pós-modernidade: entre a subversão e o neoconservadorismo}

\section{Resumo}

Este artigo examina o fenômeno do cinema pós-moderno — seu contexto e características-e sua influência na nova Hollywood. Oferecendo numerosos exemplos, propõe-se uma reflexão sobre o potencial crítico e subversivo deste para concluir que, por mais que o cinema pós-moderno ofereça ferramentas para a crítica política — particularmente a paródia—, os filmes hollywoodianos se alinham tipicamente com as ideias neoconservadoras ou acabam sendo acríticos.

\section{Palavras-chave}

Cinema, Hollywood, pós-modernidade, paródia, crítica (Fonte: Tesauro da Unesco). 


\section{Introducción: ¿Todo cine es posmoderno?}

Las siguientes líneas tienen un doble propósito. Por un lado, arrojar luz sobre la manera en que las tendencias posmodernistas han ido dominando el cine de Hollywood en las últimas décadas. Por otro, intentar desvelar las dos caras de la posmodernidad hollywoodense, es decir, la manera en la que oscila entre la crítica, la subversión y los aires renovadores y la nostalgia acrítica, la resistencia al cambio y el neoconservadurismo.

Empecemos pues definiendo una vez más qué es el cine posmoderno. La posmodernidad se nos presenta como un concepto periodizador consecutivo de la modernidad, que en lo que respecta al cine está claramente relacionado -aunque no en exclusiva- con una etapa posclásica de Hollywood. No hablamos de posmodernidad sólo por una razón puramente cronológica. En realidad, según Stam (2001, p. 344), el cine posmoderno puede atender a diferentes definiciones, a saber: una coordenada discursiva/conceptual, un corpus de textos, un estilo o estética específica, una época, una sensibilidad predominante, un cambio en los paradigmas... Ciertos teóricos, como Fredric Jameson (1991), adoptan una perspectiva multidimensional que aborda la posmodernidad simultáneamente como estilo, discurso y época, pues la posmodernidad no es sino la lógica cultural del capitalismo tardío. Es esta perspectiva multidimensional aplicada a la teoría fílmica a la que nos vamos a referir en las siguientes líneas.

Desde la concepción de que todo cine es intrínsecamente posmoderno hasta la idea de que no hay películas posmodernas per se sino lecturas posmodernas de esas películas (Zavala, 2005), existe todo un espectro en el que es difícil encontrar un punto de anclaje. Esto es así por la propia dificultad a la hora de definir la posmodernidad misma. En realidad la posmodernidad se refiere tanto a un periodo histórico como a una lógica cultural capitalista, pero también a una nueva manera de teorizar lo social y lo cultural, y, finalmente, a un movimiento estético que se extiende por todas las artes y surge como reacción a la tradición y el realismo moderno. Si bien es este último concepto el que más nos interesa, resultaría impracticable estudiar una obra posmodernista sin atender al periodo histórico, el sistema económico en el que se instaura y las teorías sociales y culturales que lo acompañan. 
Podría decirse que todo cine es en puridad posmoderno, pues la unicidad, permanencia y trascendencia que se le otorga al arte, en el caso del cine se torna multiplicidad (múltiples copias sin un original claro, pero también el pastiche que supone el montaje de una película y la subsiguiente pérdida del aura), transitoriedad (se acaba la película y salimos del cine, las imágenes se desvanecen como lágrimas en la lluvia) y anonimia del equipo que realiza el filme (si bien ésta puede ser despreciada a favor de la teoría del autor). Además el cine ha hecho efectiva la caída de la alta cultura en los dominios de la cultura popular, pues incluso los más exquisitos auteurs llegan a cosechar enormes éxitos comerciales y las obras con más ambiciones artísticas son exhibidas en centros comerciales acompañadas de palomitas y nachos con queso. Sin olvidar que el cine nació como entretenimiento para las clases populares, como espectáculo más próximo al circo o el vodevil que al teatro o la literatura, disciplinas éstas que pertenecerían a la alta cultura, y de las que, sin embargo, enseguida se nutriría (y se sigue nutriendo) el séptimo arte.

El cine es, además, el arte del pastiche por excelencia, y el montaje ese cortar, desordenar, ordenar y volver a pegar imágenes- es un recurso clave de la práctica fílmica, muchas veces considerado el único recurso puramente cinematográfico. El pastiche cinematográfico permite la ilusión de unicidad espacio-temporal aun basándose en la mixtura y la disruptividad del espacio-tiempo.

Si bien en su conocido ensayo La obra de arte en la época de su reproductibilidad técnica, escrito en la década de los treinta, Benjamin hace referencia directa a la modernidad ilustrada y la asocia a una extinción del aura del objeto artístico, para autores como Connor (1997) Benjamin está prediciendo el fin de la modernidad (al fin y al cabo, ésta se preocupa por la trascendencia de la obra de arte, el estilo propio del autor y la originalidad, es decir, el aura) y el subsiguiente paso a la posmodernidad. En efecto, la vulnerabilidad de ese aura mítica de la obra de arte no ha hecho sino acentuarse en los tiempos de la electrónica y la digitalización, tiempos que Benjamin no llegó a conocer. Sí lo hizo Jameson, quien, siguiendo la senda marcada por Benjamin décadas atrás, identificaría la 
fragmentación y la anonimia del cine con la esquizofrenia narrativa propia de la posmodernidad.

Considerar, sin embargo, que todo cine es posmoderno, distorsionaría nuestros objetivos. Jameson nos da una idea de la importancia que el concepto posmodernidad debería tener a la hora de analizar las producciones culturales contemporáneas:

\begin{abstract}
Estoy lejos de pensar que toda la producción cultural de nuestros días es "posmoderna" en el sentido amplio que daré a este término. Sin embargo, el posmodernismo es el campo de fuerza en que tipos muy diferentes de impulsos culturales (...) tienen que abrirse camino. Si no concebimos de manera general la existencia de una dominante cultural, nos vemos obligados a compartir el punto de vista que pretende que la historia actual es mera heterogeneidad, diferencia casual, coexistencia de innumerables fuerzas diversas cuya efectividad es indescifrable (1991, pp. 21-22).
\end{abstract}

Parece difícil entender que, en algo más de cien años de existencia, la práctica y la teoría cinematográfica hayan llegado ya a un momento pos-moderno, más moderno que lo moderno, más allá de todo y dando por agotadas todas las etapas anteriores. Si nos abrimos al conjunto de las disciplinas artísticas, el término posmoderno puede llegar a rastrearse en fechas tan tempranas como 1934, en una Antología de la poesía española e hispanoamericana (1882-1932) firmada por Federico de Onís, y diez años después, también en el contexto de la poesía latinoamericana, en un texto de Dudley Fitts titulado Anthology of Contemporary Latin American Poetry. De ambos textos se hace eco el exhaustivo sondeo historiográfico completado por Perry Anderson (2000). En el caso del cine, y más concretamente el cine de Hollywood, el surgimiento del posmodernismo es bastante más tardío, y llegaría unido al nuevo Hollywood, corriente acaecida en la década de los sesenta y setenta, momento en el cual Hollywood comenzaría a salir de una crisis que, con altibajos, había estado castigándolo desde el fin de la Segunda Guerra Mundial. Pero el nuevo Hollywood asociado al posmodernismo vendría a ser un tercer estadio en el devenir de la historia de Hollywood, ya que antes de éste nos encontramos con otros dos periodos identificables. 
Jameson (1992) asociaría estas tres fases de la historia de Hollywood con el devenir del capitalismo desde el siglo XVIII hasta nuestros días y sus también tres épocas diferenciadas: capitalismo de mercado, capitalismo imperialista y capitalismo multinacional, e identificaría el cine posmoderno como una consecuencia de esta tercera ola histórico-económica. Pero en lo que a las dos olas anteriores se refiere, encontrarían resonancia directa (aunque sin coincidencia cronológica real) en primer lugar en el periodo clásico, centrado en el realismo y basado en convenciones narrativas reconocibles, que marcaría el florecimiento y la expansión de Hollywood en las primeras décadas del siglo XX. El cine clásico es el cine espectacular por antonomasia, es decir, el cine que convierte cualquier experiencia humana en un espectáculo narrativo-audiovisual sometido a las convenciones establecidas por la tradición cinematográfica, y heredero también de otras tantas disciplinas artísticas como la literatura y el teatro.

André Bazin quiso poner una fecha concreta a la defunción del cine clásico: el año 1939. El teórico francés supo apreciar en esta fecha el comienzo de un giro hacia el realismo en autores como Orson Welles y William Wyler. Después del cine clásico llegaba por lo tanto el turno del modernismo, la época en la que surgen los grandes autores del siglo XX (Welles, Hitchcock, Fellini, Bergman...) y toman fuerza importantes movimientos rupturistas, como el neorrealismo italiano en la década de los cuarenta, la nueva ola francesa en la década de los sesenta o el nuevo cine alemán en la década de los setenta. Los autores de esta época realizaron sus aportaciones individuales y ofrecieron "elementos específicos derivados de su visión personal de las posibilidades expresivas del lenguaje cinematográfico” (Zavala, 2005). El modernismo se distingue por una tendencia a la ruptura y la innovación frente a la tradición del cine clásico. Las estrategias intertextuales características de toda estética de ruptura son la parodia y la metaficción. La primera tiene una naturaleza irónica y suele ser irreverente, y la segunda pone en evidencia las fronteras entre la realidad y las convenciones de toda representación.

\section{Características del cine posmoderno}

Conocer los dos periodos que anteceden al periodo posmoderno es sin duda de gran utilidad a la hora de entender las características propias de 
lo que se ha dado en llamar cine posmoderno. Este es consciente y se hace eco tanto de las convenciones cinematográficas fijadas durante el periodo clásico como de las diferentes transgresiones y rupturas llevadas a cabo durante el periodo moderno. Apuntemos, sin embargo, que estas tres etapas que estamos acotando no hacen referencia a la totalidad de la cinematografía, sino que servirían más bien para definir tendencias y tensiones más o menos preeminentes en el devenir de la historia del cine, ya que, como nos recuerda Kristin Thompson (1999), hay una parte nada desdeñable del cine contemporáneo que puede aún considerarse clásico, sobre todo desde el punto de vista narrativo.

Como explica Jameson, para inaugurar un nuevo periodo es necesario aceptar la hipótesis de que se ha producido un corte radical o coupure, y esta ruptura, según el crítico norteamericano, se aprecia en el cine a partir de "Godard y la producción pos-Godard, así como (en) el cine y el video experimentales, pero es también un tipo completamente nuevo de cine comercial” (1991, p. 15). Más adelante nos fijaremos en ese nuevo cine comercial enmarcado en el nuevo Hollywood al que hace referencia Jameson. Antes haremos un somero repaso a las características propias del cine posmoderno. Si bien la tendencia académica más extendida apuesta por analizar las características particulares de cada filme individual, antes de llegar a ese punto daremos un repaso a los grandes rasgos en los que el cine posmoderno puede reconocerse, sin olvidar que el propio sistema industrial bajo el que se rige Hollywood, las diversas conformaciones de las audiencias, los nuevos dispositivos de visión, así como la utilización de las nuevas tecnologías, aportan rasgos posmodernos insoslayables. En cualquier caso, las más evidentes características posmodernas serían las siguientes:

1) La intertextualidad y el reconocimiento de dichas alusiones por parte de la audiencia. Un juego de la memoria que cuestiona la participación y la atención del espectador, continuamente retado a identificar los textos citados y a sentirse parte de esa recolección del pasado, llegando así a sentirse más identificado con el autor y las referencias culturales que comparte con éste que con la propia historia relatada. Es lo que Noëll Carrol ha definido como 'cine de alusión' (1998, p. 
241), y se supone opera sobre espectadores con un bagaje cinematográfico importante. La alusión incluye prácticas como las citas, las conmemoraciones y reelaboraciones de géneros pasados, ciertos homenajes en forma de recreaciones de escenas clásicas, así como el uso de leitmotivs, personajes tipo, tramas, gestos y líneas de diálogo que hayan pasado a la historia del cine. Ciertas películas de Woody Allen son un buen ejemplo.

2) La autorreferencialidad, la parodia, el pastiche y otras estrategias disruptivas que distancian al espectador y proponen una nueva relación con éste. Como apunta Degli-Esposti (1998, p. 5), es notable también la atención que el cine posmoderno dedica al acto de mirar; atención que muchas veces acarrea que el mero hecho de comunicar suplante el contenido mismo de dicha comunicación. El voyerismo, la presencia constante de cámaras, los monitores y las pantallas de ordenador, las cintas de video y el videoaficionado son elementos recurrentes de las películas posmodernas, desde Blue Velvet (David Lynch, 1986) a Blade Runner (Ridley Scott, 1982).

3) Multiplicidad de estilos. Combinación, confrontación, rotación y regeneración de estilos en lo que llega a convertirse, como describe Connor (1997, p. 198), en una furiosa polifonía de voces descontextualizadas. Polifonía en la cual la idea del autor-creador como originador de todo queda desfasada. La fragmentación y mezcolanza propia del estilo posmoderno vendría a ser un reflejo de la fragmentación de los propios sujetos. Esto implicaría que la mente del autor ya no es lo suficientemente estable para ser la fuente de un estilo personal, lo que conllevaría el perpetuo préstamo y mestizaje propio del pastiche.

4) Uso de la ironía, no como instrumento distanciador e incluso políticamente subversivo (tal y como pretendiera el cine moderno), sino como cuestionamiento de la verdad y de toda autenticidad, muchas veces vaciada de sentido crítico y limitada a una mímica neutra. De esta forma es fácil llegar al extremo del tongue-in-cheek, que lo toma todo a broma, que se ha resignado a no poder cambiar nada y que nos pide que tomemos la película y su contenido de la misma manera. 
5) La nostalgia y su exaltación: una revisitación a la superficie de las cosas pasadas como reacción al desencanto de los hechos contemporáneos o, según Jameson, "la canibalización aleatoria de todos los estilos del pasado, el juego de la alusión estilística azarosa” (1996, p. 39) que paradójicamente elimina la sensación de origen histórico. La memoria, de acuerdo con Huyssen (1995, p. 24), funciona como baluarte que defiende a los sujetos posmodernos del miedo a la obsolescencia y la velocidad del cambio. En el cine posmoderno esta función toma la forma de revisitaciones de géneros clásicos, estética retro, remakes, secuelas y precuelas, junto a una creencia de que cualquier cine pasado fue mejor. Su máximo exponente sería el cine de nostalgia o retrofilm, y en el caso de Hollywood los filmes que buscan el sabor perdido de la década dorada de décadas pasadas (especialmente, la década de los cincuenta), que más que recrear, cuestionar o recordar una época concreta, lo que busca es revivir en el espectador una experiencia cultural de ese periodo histórico en particular.

\section{La posmodernidad en el nuevo Hollywood}

La posmodernidad cinematográfica no es sólo un fenómeno hollywoodense, claro está. Multitud de películas europeas (las películas del galés Peter Greenaway, del finés Aki Kaurismäki, la práctica totalidad del cine de Almodóvar, por nombrar sólo unas pocas) han recibido unánimemente la calificación de posmodernas. Igualmente, películas que se alejan radicalmente de las convenciones hollywoodenses, como Blue Velvet (David Lynch, 1986) o Pulp Fiction (Quentin Tarantino, 1994), son a menudo expuestas como paradigmas del cine posmoderno. Sin embargo, tradicionalmente, y con base en un deslizamiento paulatino que trataremos de describir, el título posmoderno se ha venido adecuando a la producción hollywoodense de las últimas décadas con fabulosa asiduidad.

Aunque el concepto posmoderno surge del arte y se aplica en un principio a las diferentes disciplinas artísticas, cuando Jameson -primer crítico en considerar la posmodernidad en términos históricos y estéticos- habla de la posmodernidad como una dominante cultural, una nueva manera de vivir y leer la sociedad contemporánea, lo hace apelando direc- 
tamente al cine de Hollywood, y es el corpus de películas hollywoodenses el que le sirve como ejemplo para ilustrar esta nueva lógica cultural. Baudrillard hace lo propio, y toma como referencia y objeto de estudio la hasta entonces denostada cultura de masas por antonomasia, la cultura de masas norteamericana, sin olvidar que esta cultura tiene en Hollywood uno de sus máximos pilares.

Como resalta Roberta Garrett (2007, p. 19), desde críticos tempranos inmediatamente posteriores a Jameson, como Noël Carroll, Norman Denzin y Jim Collins, hasta los usos que hoy en día se hacen de la llamada posmodernidad, tienen en perspectiva el cine comercial de Hollywood, y puede decirse que, al día de hoy, la teoría posmoderna ha abandonado unánimemente el terreno del cine de arte y ensayo y, quizá en menor medida, el cine europeo, para centrarse en el cine comercial por antonomasia. John Hill (1998) afina aún más, y se refiere en exclusiva a los blockbusters o grandes superproducciones hollywoodenses cuando habla de productos típicos del periodo posmoderno. Ciertamente, si la posmodernidad es la lógica cultural del sistema económico hegemónico -el capitalismo transnacional-, parece asumible que sea el cine de Hollywood (tanto cultural como económicamente hegemónico) el que se haga eco de esta nueva estética.

Pero volvamos a Jameson, quien se basó en la periodización del capitalismo propuesto por Ernest Mandel en su conocida obra Late Capitalism (1975) para, en analogía a ésta, proponer asimismo una minicronología de la historia del cine, y más concretamente del cine de Hollywood, como ya hemos explicado. De esta manera, el florecimiento de la industria de Hollywood coincidía con la primera etapa realista del cine y el surgimiento de un nuevo Hollywood vendría a marcar la era posmoderna de este tríptico. En medio, una época llamada moderna, marcada por la ruptura y la fuerte personalidad de ciertos autores clave. Creemos, por lo tanto, que la asociación posmodernidad-Hollywood está plenamente justificada y es pertinente si hablamos de una dominante cultural, pues la industria audiovisual norteamericana ha demostrado con creces su poder para establecerse y articularse como cultura mediática global desde una posición hegemónica. 
¿Cuándo penetran las tendencias posmodernas en Hollywood? Diversos autores coinciden: la posmodernidad pone punto final al radicalismo de los años sesenta y setenta, al espíritu del 68 y la idea de que el marxismo es el único horizonte teórico legítimo. La industria de Hollywood no está sola en este declive del izquierdismo, claro está. Como señala Stam (2001, pp. 341-342), Cahiers du Cinéma abandona en los ochenta la crítica marxista para volver a la más aséptica teoría del autor, cesan los neofrankfurtianos ataques al aparato opresivo hollywoodense y a la alienación que éste trae consigo, y los teóricos reunidos en torno a la revista Tel Quel se deciden a celebrar el liberalismo a la americana. En Estados Unidos, además, se da una generalizada vuelta a valores ultraconservadores encarnados en el presidente Ronald Reagan y articulados en torno a la patria, el militarismo y, sobre todo, el patriarcado.

Pero en el terreno hollywoodense, los cambios han venido fraguándose desde mucho antes. En 1948 se dio la resolución del llamado Paramount Case, una sentencia de la Corte Suprema de Estados Unidos que obligó a terminar con el monopolio de los grandes estudios, y que trajo el declive de éstos, así como una nueva manera de hacer películas, coincidiendo, curiosamente, con la oportunidad que una Europa en ruinas tras la guerra suponía de cara a la exportación cinematográfica. Esta época de cambios estructurales en Hollywood vino además marcada por el baby boom de la posguerra y el consecuente nacimiento de un floreciente y jugoso mercado centrado en el teenager y la juventud, deseada y perseguida audiencia. Pero no menos importante es la aparición de la televisión y su rápida e imponente incorporación a la vida diaria del norteamericano medio en los años cincuenta, rival en un principio y promotora más tarde del cine de Hollywood. A la televisión habría de seguir el vídeo casero en los años setenta (el formato Betamax de Sony empezaría a comercializarse en 1975), y la televisión por cable y satélite en la década siguiente.

Durante estas décadas Hollywood parece buscarse a sí mismo, y no es sino hasta mediados los años setenta cuando empieza a perfilarse un nuevo Hollywood. En estos años, gigantescas operaciones financieras, que convierten los estudios de Hollywood en meras porciones de grandes con- 
glomerados industriales que abarcan todas las parcelas de la industria del entretenimiento (y alguna más), así como los avances tecnológicos y los cambios demográficos, gestan lo que habrá de llamarse el nuevo Hollywood. Una nueva manera de enfocar el movie business basada en grandes producciones de altísimo presupuesto, repletas de los más descomunales efectos especiales, promocionadas con las más agresivas técnicas de marketing y la estrategia de la saturación en salas.

Paradigma de este nuevo cine es Tiburón (Jaws, Steven Spielberg, 1975), el primer filme considerado high-concept, es decir, película no basada en una idea, trama o historia, sino más bien en un concepto básico, rápido de transmitir (tanto al productor mediante el pitching como a la audiencia, mediante los tráilers publicitarios) y fácil de digerir, y donde los efectos especiales y la acción desenfrenada priman por encima de la trama o la construcción de personajes. Tiburón pasó así a ser un blockbuster en toda regla que superaría los 100 millones de dólares en su presupuesto y se estrenó rompiendo todos los récords en 464 salas norteamericanas simultáneamente, coincidiendo con las vacaciones veraniegas y de la mano de una campaña de marketing sin parangón hasta la fecha. La saga Star Wars (comenzada en 1977) vendría a confirmar la preeminencia de este nuevo cine, muy marcado además por lo que Richard Maltby ha denominado como la ‘juvenilización’ del cine norteamericano y su audiencia.

Si bien sería un error afirmar que el nuevo Hollywood es sinónimo de posmodernismo en el cine norteamericano, sí es pertinente señalar que ambas fuerzas convergen, coinciden $y$, en cierta manera, se apoyan la una en la otra, e incluso se ofrecen cobertura teórica mutuamente. Si la posmodernidad es el conjunto de contingencias socioeconómicas en el mundo actual, tales como la globalización de los mercados, el desarrollo de la tecnología y las redes de información, el triunfo de la sociedad de consumo, la crisis ecológica y un desengaño político-utópico generalizado, estas características también apoyan y nutren el nuevo Hollywood, desde la industria que lo sostiene hasta las temáticas en las que se apoya, pasando por las conformaciones sociodemográficas de su audiencia. El arte posmodernista tiende a caracterizarse por una narrativa disruptiva, una visión negra y pe- 
simista de la condición humana, una representación masiva e injustificada de la violencia, la muerte del héroe y, en general, un énfasis desproporcionado en la técnica por encima del contenido, que es precisamente la característica principal del high-concept film, paradigma del nuevo Hollywood.

La cronología nos ayuda a entender la coincidencia del posmodernismo hollywoodense con esta nueva manera de organización del negocio audiovisual llamado nuevo Hollywood. Precisamente, esta nueva condición surgió como tercera fase de un devenir emprendido con el cine clásico de Hollywood y prolongado por una época de transición artísticamente ambiciosa y políticamente progresista llamada New American Cinema o Hollywood Renaissance, y protagonizada por directores como Arthur Penn, Martin Scorsese, Francis Ford Coppola, Robert Altman y Peter Bogdanovich. Este periodo de transición fue breve (1967-1976), y se caracterizó, como señala Glen Mann (1994), por un descarnado escrutinio del paisaje mítico y moral de la escena norteamericana de manera tan franca como permitían las condiciones comerciales de la industria cinematográfica y su audiencia. Se trataba de una industria en transición, desorientada por los cambios en la conformación de la audiencia (cada vez más heterogénea y difícil de atraer) y castigada por una crisis estructural que la azotaba desde el final de Segunda Guerra Mundial. Los estudios, sin un rumbo marcado, parecían más abiertos entonces a las propuestas de una nueva generación de directores y productores de tendencias más heterodoxas. Pero no sólo eso. Por primera vez en la historia de Hollywood (al menos de manera significativa) los negros se hicieron detrás de la cámara para contar historias desde su marginada posición, y las mujeres, como por ejemplo Barbara Loden, se embarcaron en la dirección de películas para mostrar representaciones de las mujeres en un contexto de opresión patriarcal nunca antes descubierto (Ryan y Kellner, 1988, p. 8).

El cine producido durante este periodo no hace sino representar e inspirarse en un clima sociopolítico convulsionado por la lucha a favor de los derechos civiles, por la emancipación de los negros, las mujeres y los homosexuales, y por la guerra de Vietnam: este clima sin duda favoreció su emergencia, pero también marcó su fin. Y es que el ulterior periodo pos- 
moderno viene marcado más bien, como habremos de explicar, por una reacción con los movimientos izquierdistas de la década de los sesenta, incluidos los movimientos feministas.

Como apunta Geoff King (2002, p. 2), a este periodo de transición también se le conoce como nuevo Hollywood, denominación que sólo puede llamar a confusión y que, por ello, en estas líneas, nos reservamos para el período posterior que ya hemos acotado, y que, en realidad, se extiende hasta nuestros días, en concomitancia directa con la posmodernidad. Para añadir más confusión, el Hollywood Rennaissance y el nuevo Hollywood comparten autores: directores de cine que comenzaron su carrera con filmes políticamente progresistas o transgresores y se deslizaron paulatinamente hacia el terreno mainstream y políticamente más conservador. Tal es el caso de Martin Scorsese, cuyo filme El cabo del miedo (1991) pasaremos a analizar en tanto ejemplo de este deslizamiento posmoderno hacia posturas que han sido calificadas incluso como 'misóginas'.

\section{Subversión, neoconservadurismo y posmodernidad}

Desde que el término posmodernidad se popularizó en los diversos círculos de debate, una cuestión ha resurgido recurrentemente: ¿es la posmodernidad un movimiento reaccionario, antimoderno, o por el contrario una fuerza liberadora y progresista?

Una discusión similar es trasladada con gran presteza a la teoría fílmica, y así son identificados dos periodos en la historia de Hollywood que por cronología y estilo pueden ser solapados, pero que tras un examen más exhaustivo se revelan como dos movimientos antagónicos: uno subversivo y en sintonía con los movimientos contraculturales nacidos en los años sesenta, otro conservador y valedor de lo que después habría de llamarse la nueva derecha imperante en la década de los ochenta. Hablamos, claro está, del Hollywood Renaissance, encarnado por una nueva generación de cineastas que dieron vida a un movimiento inmediatamente anterior al nuevo Hollywood, que incluso pasaron después a encarnar dicho movimiento, y que es por lo tanto confundido con éste. Pero ya hemos aclarado 
anteriormente que nos referimos a dos movimientos bien distintos. Uno, el New American Cinema o Hollywood Renaissance, se identifica a partir del final de la década de los sesenta con las luchas juveniles y los movimientos políticos de izquierdas. Spartacus (Stanley Kubrick, 1960), Bonnie and Clyde (Arthur Penn, 1967), Easy Rider (Dennis Hopper, 1969) y The Last Picture Show (Peter Bogdanovich, 1971) podrían tomarse como ejemplos de películas que guardan dicha afinidad ideológica.

Pero a mediados de los setenta, la tendencia declinó y, aunque con similares recursos estilísticos y genéricos (principalmente el cine de alusión y la mixtura de lo considerado alta cultura con la cultura popular), ciertos filmes empezaron a alinearse más con el high-concept de alto presupuesto que con los movimientos contraculturales de la década precedente. Incluso en el llamado cine independiente más alejado del high-concept, porción nada desdeñable del cine de Hollywood desde el final de la década de los ochenta, la supuesta incorrección política y los temas progresistas no suelen pasar de ser una mera coartada o argumento de venta. Levy (1999, p. 55) tiene claro que, en general, las películas independientes no son ni estéticamente rompedoras ni políticamente provocadoras, aunque sí les concede el haber tocado temas (la homosexualidad, las tensiones raciales, la pena de muerte... ) que el otro Hollywood no tendría interés en mostrar al gran público.

Así, de un alusionismo asociado a la autoconciencia crítica se pasa a un cine de alusiones que alimenta una nostalgia acrítica y decadente, una nostalgia que hace uso de anticuados y antiliberales valores culturales ya exprimidos por el cine de Hollywood en otros periodos, como el heroísmo, la celebración tradicional de la masculinidad y la superioridad cultural occidental. Belton (1996, p. 52) se refiere a esta nueva corriente como un cine estilísticamente juvenil e ingenioso pero políticamente conservador, y añade que, más que expresar ideas, se limita a la cita, el reciclaje y la alusión vacía. De la misma opinión es Carroll (1998, p. 263), quien afirma que sin la utopía como meta todo cine de alusión pierde su encanto, se degrada hasta la simple nostalgia y, en el peor de los casos, puede ser llanamente un fraude, pues el espectador cree estar participando de la importancia sociocultural de los filmes de los sesenta y primeros setenta cuando en realidad no está sino viendo un eco vano de aquello. 
Ryan y Kellner (1988, p. 9), por su parte, asocian cada momento artístico con su contexto económico particular. Así, mientras el renacimiento hollywoodense a manos de los nuevos talentos vino marcado por una época de prosperidad también en lo económico, que hizo posible la simpatía por valores liberales y progresistas, a mediados de los setenta circunstancias como la crisis del petróleo, la reconversión industrial y una recesión generalizada afectan directamente a la industria de Hollywood, y la hicieron retraerse hacia posturas más conservadoras en la manera de afrontar la producción cinematográfica. Surgieron nuevos géneros habitualmente asociados al conservadurismo -las películas de terror y las de desastres- y se reinventaron otros géneros cuya fórmula del éxito parecía asegurada, como el cine de aventuras y la ciencia ficción. Si los pobres y los negros eran presentados como víctimas en el cine de tendencias izquierdistas de los sesenta, en los setenta volvieron a las pantallas como maleantes y elementos perturbadores del orden público en películas como Harry el Sucio (Dirty Harry, Don Siegel, 1971).

Otro tanto ocurre con las mujeres, cuyas reivindicaciones parecen ir calando en el cine de los años sesenta. En la década siguiente, no obstante, la crítica feminista se ocupó especialmente de denunciar las estrategias del género de terror, por entenderlo como un género especialmente reaccionario donde el psicópata asesino tiende a eliminar a todos aquellos ( $y$, sobre todo, a todas aquellas) que se salen de los parámetros sociales más conservadores, especialmente aquellos relacionados con la sexualidad. El esquema general propone que la chica que se mantiene al margen de cualquier tentación sexual, en un estado de virginal prepubescencia, sea la única que consigue salvarse al final, tal y como ocurre en La matanza de Texas (The Texas Chain Saw Massacre, Tobe Hooper, 1974). Por otro lado, también fue criticado desde la teoría fílmica feminista un leitmotiv recurrente según el cual el origen de la locura asesina del psicópata se encuentra siempre en una mujer, generalmente la madre o una hermana. Ocurre así en Psicosis (Psycho, Alfred Hitchcock, 1960) o La noche de Halloween (Halloween, John Carpenter, 1978). Las mujeres acaban siendo víctimas e instigadoras de la violencia del hombre. Barbara Creed habrá de clasificar freudianamente a estas mujeres como mujeres castradoras (1993, p. 156), productos del terror masculino que el psicoanálisis tan aplicadamente ha descrito. 
La vuelta a valores conservadores como el patriarcado, la autoridad masculina y el individualismo por encima de todo no se dio exclusivamente en los géneros del horror y catástrofes. Ryan y Kellner (200) también identifican temas reaccionarios en aclamadas películas de los auteurs más prestigiosos de la época, como El cazador (The Deer Hunter, Michael Cimino, 1978) y Apocalipsis ahora (Apocalypse Now!, Francis Ford Coppola, 1979), películas pos-Vietnam que, sin embargo, no muestran haber aprendido ninguna lección sobre la desastrosa política neocolonialista del gobierno, sino que más bien tienden a utilizar el escenario bélico como marco para enaltecer el militarismo heroico masculino.

\section{Los peligros de la familia posnuclear: El cabo del miedo (1991)}

En 1991 el director italoamericano Martin Scorsese realizaba un remake de la película de 1962 El cabo del terror (Cape Fear, J. Lee Thompson) y entraba de lleno en el mainstream después de labrarse una carrera como auteur del New American Cinema. Realizaba asílo que ha sido considerada generalmente como una revisitación de su antecesora, aportando un claro barniz posmoderno (Boggs y Pollard, 2003, p. 113) o una reelaboración del mismo tema desde el prisma del escepticismo posmoderno (Sherwin, 2000. p. 172). En efecto, el etos posmoderno, presente de principio a fin, se canaliza mediante una estética determinada, una permutación del género cinematográfico (del noir original al puro terror con toques de melodrama sirkiniano), un juego intertextual que apela tanto a la primera versión de $E l$ cabo del miedo como a numerosas películas, y sobre todo mediante la ironía y la visión ambigua e inestable de la familia nuclear, las relaciones padre-hija y la idea de ley y la justicia, el crimen y el castigo.

La historia arranca con la salida de prisión del violador Max Cady, dispuesto a vengarse de su abogado defensor por haber enterrado un informe que podría haberle ahorrado muchos años de cárcel. El abogado en cuestión es Sam Bowden (Nick Nolte), padre ejemplar en la primera versión del filme y adúltero en esta segunda. Su ética profesional también queda en entredicho en la historia que nos narra Scorsese, ya que, enterrando el informe, no cumplió con integridad su tarea de defender celosamente a 
su cliente (por mucho que el espectador simpatice con su acción) y en la actualidad también manipula formalismos para beneficiar a la hija de un colega en un caso de divorcio. Frente a la imagen de familia nuclear blanca enfrentada a un peligro externo, Scorsese propone una familia inestable de cuyo mismo núcleo y origen manan las amenazas y los miedos. Desde la lectura freudiana que realiza Nicholls, el principal pecado de Bowden sería desatender sus tareas como patriarca, tarea que implicaría mantener el orden y regular la sexualidad de todos los miembros de la familia (Nicholls, 2004, p. 132). El peligro externo, Max Cady, supondría así un catalizador de todos los peligros que alberga la propia familia y la consecuencia lógica de la falta de autoridad y rectitud de Sam.

Esta ambivalencia respecto al bien y el mal se hace patente en la elección irónica del casting. Scorsese recupera al actor que encarnó al psicópata Cady en la primera versión de la película, Robert Mitchum, pero esta vez para representar al teniente de la policía que ayuda a Sam a protegerse de Cady. En una nueva vuelta de tuerca, el teniente sugiere sutilmente a Sam un atajo para acabar con Cady, poniéndose en una posición ambigua respecto a la línea que separa la legalidad y la ilegalidad. También el primigenio e íntegro Sam Bowden, el actor Gregory Peck, es recuperado para un cameo, en este caso como abogado criminalista defensor de Cady, cuando éste denuncia a Sam Bowden por amenazas y agresión. El casting irónico se completa con la aparición de Martin Balsam, antaño jefe de policía y ahora juez sureño caricaturizado. En este juego típicamente posmoderno de referencialidades, se pone de manifiesto que el bien y el mal son conceptos permeables. De esta manera, la primera versión resulta, más que homenajeada, burlada o, cuando menos, contestada.

En la familia Bowden todos esconden algo. El padre, sus infidelidades y sus tejemanejes legales. La madre (Jessica Lange), su crisis nerviosa y el arrepentimiento por una vida perdida junto a un marido infiel. Y la hija de quince años, Danielle (Juliette Lewis), un (insano) interés sexual por Max Cady, así como unos recuerdos de infancia que pretende enterrar.

Es precisamente mediante los recuerdos de la hija que la historia nos es narrada de principio a fin, una aportación de la versión de Scorsese. Es 
Danielle quien comienza lo que parece será un idílico recuento de sus días de verano en el Cabo del Miedo y el barco que la familia posee en el río del mismo nombre. La imagen de Juliette Lewis se nos ofrece primero en negativo, para pasar seguidamente a positivo y mostrarnos la imagen de una niña castamente vestida de colegiala. El corte nos lleva directamente a la celda de Cady. La multitud de contrastes, así como la confesión de que lo relatado son los recuerdos de una niña asientan la idea de que no hay que fiarse de lo que suceda a continuación. ¿Todo sucede tal y como lo relata la hija? ¿Cuánto hay de pesadilla o de fantasía en lo relatado? El filme no ofrece manera de saberlo con seguridad.

En cualquier caso, Danielle parece que va a referirse a los días dorados de su niñez justo cuando ésta ya ha acabado. Y lo que viene tras la niñez resulta ser un periodo de inestabilidad, deseos sexuales confusos y violencia extrema. Si en la primera versión del filme, tanto la hija como la mujer de Bowden eran meras herramientas que Cady planeaba utilizar para destruir al abogado, en esta nueva propuesta ambas mujeres cobran autonomía y desarrollan una especie de atracción-repulsión por Cady, atracción más marcada en el caso de la hija adolescente. Pero primero es Leigh quien parece esperar a Cady. Cuando por fin se encuentran frente a frente, la mujer confiesa las ganas que tenía por conocerlo. Cady manifiesta en ese momento lo que los une a ambos: la traición de Bowden, que los ha hecho infelices por igual. En una escena previa, tras hacer el amor con su marido, Leigh se levanta y, frente a un espejo triple, se pinta sensualmente los labios y después se expone frente a la ventana. Es la primera vez que ve a Cady, subido a la tapia de su propiedad con los fuegos artificiales del 4 de julio como telón de fondo. Avergonzada, Leigh se limpia los labios tras avisar a su marido, un gesto que obtendrá eco cuando Cady bese a su hija, en una de las escenas más comentadas del filme, y se limpie los labios de la misma manera.

La mencionada escena se desarrolla en el teatro del colegio de Danielle, hasta donde Cady ha atraído a la chica haciéndose pasar, en conversación telefónica, por su profesor de arte dramático. El supuesto profesor ofrece marihuana a Danielle, le habla de libros prohibidos (la trilogía de Henry Miller Sexus, Plexus y Nexus) e intenta confraternizar con ella. Dan- 
nielle enseguida descubre la verdadera identidad de Cady pero eso no la hace rechazarlo, sino que la complicidad entre ellos sigue en aumento. Danielle por fin cree atisbar compresión e integridad en la figura de un adulto, cosa que no consigue con sus padres. Como le dice Cady, entre ellos no hay rencores. En realidad, Danielle debería guardarles rencor a sus padres por haberse puesto furiosos cuando descubrieron que su hija fumaba marihuana y la castigaron en consecuencia. Tal y como Cady lo expresa, "la castigaron por sus propios pecados", lo cual es cierto, ya que por una conversación anterior sabemos que el matrimonio también acostumbraba a fumar y que en realidad no les parece tan terrible. Esta comprensión por parte del adulto va encandilando a la chica hasta el punto de dejar que Cady la toque y la bese. De vuelta en casa, sus padres descubren que ha estado con Cady por la marihuana que encuentran en un libro de texto. Cuando Bowden acude a la habitación de su hija para indagar sobre lo ocurrido exactamente, Danielle insiste en que "ese hombre no me acosó en ningún momento, aunque tú prefieras pensar que sí”, lo que desata la ira de su padre hasta el punto de que le tapa la boca violentamente (la misma boca que Cady ha besado) mientras le pregunta obsesivamente si Cady "la tocó", un trato que asusta mucho más a su hija que el beso de Cady.

Para Kirsten Thompson este arrebato de ira se entendería como una traición de los celos que Bowden siente por Cady, al sospechar que éste ha conseguido conectar tanto intelectual como eróticamente con la adolescente, así que sus deseos incestuosos se sumarían a sus desmanes legales y a sus infidelidades matrimoniales (Thomson, 2007, p. 39). De hecho, la conversación con la hija comienza con la turbación del padre al verla en la cama sin apenas ropa: "Haz el favor de vestirte, ya no eres una niña", le pide. Ya antes Bowden ha sugerido que su hija "se volverá loca" por su nuevo profesor de arte dramático, sin saber que ése va a ser precisamente el papel que adopte Cady para acercarse a su la chica. En la misma conversación el abogado dice no entender por qué se ha montado un escándalo porque su hija fume marihuana, y su mujer le recuerda tantas otras cosas prohibidas en nuestra cultura, la primera de ellas "el incesto". Cuando Bowden y Leigh discuten por Lori, incipiente amante del abogado (en el hospital por una agresión sexual a manos de Cady), el hombre intenta exculparse afirmando que Lori 
es "una cría" a lo que su mujer responde con un cínico "a ti eso no te detendría”. También Cady (violador de una adolescente de dieciséis años) le ha sugerido a Bowden la suerte que tiene por tener en casa a una chica adolescente. "A esa edad son estupendas" comenta, mientras señala a un grupo de colegialas. De esta manera Cady parece verbalizar lo que Bowden reprime: el deseo por su hija adolescente.

Cady representa las perversiones de Bowden como padre, marido y abogado. Ciertamente, uno es el negativo (sugerido en tres ocasiones mediante el negativo fotográfico) del otro, aunque no siempre está claro quién es quién. El único objetivo de Cady es ser igual a Sam: en cultura, en estatus social, en posesiones materiales y afectivas. Habiéndolo perdido todo en prisión, quiere que Sam experimente el mismo sentimiento de pérdida. Cady arrebata a Bowden sus mujeres. Cook sugiere que lo que Cady hace en realidad es victimizar a las tres mujeres que Bowden ha victimizado previamente, consiguiendo además que estas mujeres sientan cierta atracción por Cady, como si de su ángel vengador se tratara (Cook, 1993, p. 136). Por un lado está la colega y potencial amante de Bowden, Lori, a la que el abogado da plantón y Cady viola después. Cuando Lori y Bowden juegan squash, éste le agarra por la muñeca de manera similar a la que Cady la agarra después por la muñeca, con consecuencias mucho más trágicas. Sin embargo, es el rencor que siente Lori como mujer despechada el que la lleva a la cama con Cady. Tambien Leigh confiesa curiosidad primero (como ya hemos apuntado) y empatía después por Cady, al que desvela el cruel destino que los une: una vida perdida por culpa de Bowden. En la cama con su marido, Leigh confiesa que espera la intervención de Cady para saber lo fuertes que pueden llegar a ser. De la misma manera Danielle, doble víctima de su padre (por sus castigos y sus deseos incestuosos), conecta con Cady en un primer momento. En realidad, parece divertida por la turbación que Cady está causando a su padre y eso la hace ponerse de su parte. No confiesa lo que verdaderamente ha ocurrido en el teatro de la escuela y después recoge y esconde un libro (Sexus) que Cady deja en la casa para ella, estableciendo un código secreto entre ellos que Danielle tratará de utilizar más adelante para salvarse. El hecho de que las tres mujeres de la película parezcan ansiar en cierta medida su propia violación por parte 
de Max Cady ha sido uno de los elementos más contestados por la crítica feminista. Pam Cook ha llegado a decir que El cabo del miedo es la película más misógina de la filmografía de Martin Scorsese (Cook, 137). Especialmente preocupante para Cook resulta la idea sugerida de que todo podría ser en realidad la fantasía erótica de una adolescente.

No obstante, para cuando la familia ha llegado al barco huyendo de Cady, Danielle ya parece haberse dado cuenta de lo verdaderamente peligroso que es Cady, sobre todo al descubrir el cadáver de la criada latina. Aun así, intenta hacer uso de la intimidad y complicidad que en principio compartín haciendo creer a Cady que se ha aprendido fragmentos del libro que éste le ha dejado. La treta no sale bien y desde este momento las dos mujeres tratarán de atacar a Cady (hasta dos veces quemará Danielle al convicto, con escaso éxito), al igual que lo hará el padre. Por más que la familia ataque a Cady, será al final la fuerza de la naturaleza, el propio río Cabo del Miedo, el que acabe tragándose para siempre a un sobrenatural Cady. Bowden se lavará las manos en el mismo río. Su mujer e hija renacerán del barro. Pero la familia, aunque superviviente, tendrá un nuevo trauma que ocultar para poder seguir adelante.

El personaje de Danielle está construido con claras reminiscencias lolitescas. La trama se desarrolla en el verano en que Danielle parece despertar a su sexualidad, y esta sexualidad es presentada como un peligro (una debilidad más de la familia problemática) y como antinatural. Es el peligro que detecta su padre cuando le dice que se ponga más ropa encima o su madre, cuando insta a Danielle a meterse en casa para no exponerse a la mirada de Cady. El peligro que siente el espectador cuando Danielle se reúne con el 'lobo feroz' en un escenario de cuento infantil (el teatro de la escuela) y parece disfrutar del encuentro. De hecho, el contraste entre el mundo infantil y el peligro que la sexualidad adulta representa es enfrentado continuamente, siendo la escena en el teatro escolar el más claro exponente. Pero también el osito de peluche que el detective privado encargado de cuidar de la familia utiliza como chivato para una posible irrupción de Cady en la casa cumple la misma función simbólica. El objeto infantil pierde su sentido inicial y se convierte en el termómetro que habrá de marcar la intensidad del peligro al que está expuesta la familia. 
En este sentido, la película que la familia Bowden va a ver al comienzo del filme, y que supone también el primer encontronazo con Max Cady, ya apunta en esta dirección. Se trata de Este chico es un demonio (Problem Child, Dennis Dugan, 1990), que es a su vez una parodia cómica de La mala semilla (Bad Seed, Mervyn Leroy, 1956), películas ambas que hablan de la destrucción de la familia por uno de sus niños (una niña en el caso del filme de 1956). La localización sureña (muy del gusto del dramaturgo Tennessee Williams) refiere además a un número considerable de filmes en los que la sexualidad de una joven irrumpe precoz y abruptamente, condicionando e incluso poniendo en peligro la vida de quienes la rodean, como pueden ser Baby Doll (Elia Kazan, 1956), En el calor de la noche (In the Heat of the Night, Norman Jewison, 1967) o Pretty Baby (Louis Malle, 1978).

Por más que nos hayamos detenido a desentrañar las características posmodernas del filme, no puede decirse que en lo que se refiere a la construcción del personaje de Danielle los clichés hayan sido subvertidos. La adolescencia femenina como peligro latente, así como la misma participación de la chica en su propia explotación (por lo menos en un principio), siguen presentes en toda la película. En un giro puramente posmoderno, sin embargo, Danielle 'despierta' de su fantasía y resulta ser la más agresiva contra Cady. Este final nos acerque al tema del rape revenge posmoderno y da alas a la rabia femenina con potencial subversivo.

\section{Una de cal y otra de arena: como conclusión}

Una de las características del posmodernismo cinematográfico es la parodia, de cuyo espíritu satírico puede esperarse la capacidad para la rebelión. Hutcheon (1986-87, p. 78) define la parodia como una repetición hecha desde la distancia crítica que pretende, desde una supuesta similitud, señalar irónicamente las diferencias. No está claro si de la parodia que El cabo del miedo realiza de su antecesora puede esperarse capacidad para la rebelión.

Quizá lo más reseñable del cine posmoderno es su absoluta flexibilidad y permeabilidad con respecto al clima político, económico y social en el que se inscribe. Así, utilizando aparentemente los mismos recursos (por ejemplo, la parodia y las referencias cruzadas), el cine de Hollywood es ca- 
paz de crear filmes críticos y también conservadores. Es el caso del filme en el que nos hemos detenido. La estrategia de Scorsese pasa por retorcer los clichés básicos de la película en la que está basada (la separación clara entre el bien y el mal, la figura del padre como protector y guarda de sus mujeres) y subvertirlos, pero esta subversión está lejos de ofrecer conclusiones progresistas: perdida la autoridad paterna, la familia se desmorona, la sexualidad femenina se descontrola y se convierte en víctima de peligros externos. La masculinidad en crisis de la que tanto se hablaba en los años noventa se presenta como clara amenaza en este filme. En este contexto, las críticas hechas por autoras feministas a las que nos hemos referido cobran todo su sentido. Pero estas críticas parecen obviar el final de la película, que empodera a las dos mujeres de Bowden, y especialmente a la adolescente, que llega atacar a Cady virulentamente, en una articulación de la rabia femenina que, en otras películas, se ha aplaudido en tanto paso adelante en la representación de la mujer. El filme ofrece, por lo tanto, una de cal y otra de arena: un canto fúnebre la autoridad masculina y una parodia de esta misma autoridad; una espectacularización de la violencia contra las mujeres y un nuevo horizonte en el que las mujeres podrán responder a su propia explotación sin esperar al caballero con armadura dorada.

En su apuesta por seguir siendo la fábrica de sueños global, Hollywood hace eco de la estética y sensibilidad propia del capitalismo tardío, es decir, de la posmodernidad, y deja abierta la cuestión ideológica, generalmente en manos del espectador, quien, con mayor o menor bagaje crítico, sabrá seguir las oscilaciones y ambigüedades de los filmes posmodernos.

\section{Referencias}

Belton, J. (1996). Movies and Mass Culture. Londres: Althone.

Benjamin, W. (1982). "La obra de arte en la época de su reproductibilidad técnica”. En: Discursos interrumpidos I. Madrid: Taurus.

Boggs, C. y Pollard, T. (2003). World in Chaos. Social Crisis and the rise of postmodern Cinema. Lanham: Rowman y Littlefield. 
Carroll, N. (1998). Interpreting the moving image. Cambridge: Cambridge University Press.

Connor, S. (1997). Postmodernist Culture. An Introduction to Theories of the Contemporary. Oxford: Blackwell.

Cook, P. (1993) "Cape Fear and Femininity as Destructive Power”. En: Cook, P. y Dodd, P. (eds). Women and Film: A Sight and Sound Reader (pp. 132-138). Filadelfia: Temple UP.

Creed, B. (1987). "From Here to Modernity: Feminism and Postmodernism”. En: Screen 28 (2), pp. 47-67.

Degli-Esposti, C. (ed.) (1998). Postmodernism in the Cinema. Oxford, Nueva York: Berghahn Books.

Garrett, R. (2007). Postmodern Chick flick. The Return of the Woman's film. Nueva York: Palgrave Macmillan.

Hill, J. (1998). "Film and postmodernism". En: The Oxford Guide to Film Studies. Oxford: Oxford University Press.

Hutcheon, L. (1986-87). “The Politics of Postmodernism: Parody and History”. En: Cultural Critique, 5, pp. 179-207.

Huyssen, A. (1995). Twilight Memories: Marking Time in a Culture of Amnesia. Nueva York: Routledge.

Jameson, F. (1991). El posmodernismo o la lógica cultural del capitalismo avanzado. Barcelona: Paidós.

Jameson, F. (1992). Signatures of the Visible. Nueva York: Routledge.

Jameson, F. (1996). Teoría de la posmodernidad. Madrid: Trotta.

King, G. (2002). New Hollywood Cinema: An Introduction. Londres y Nueva York: IB Taurus. 
Levy, E. (1999). Cinema of Outsiders: The Rise of American Independent Film. Nueva York y Londres: NYU Press.

Maltby, R. (1998). "Nobody Knows Everything: Post-classical Historiographies and Consolidated Entertainment”. En: Neale, S. y Smith, S. (eds.). Contemporary Hollywood Cinema. Londres: Routledge.

Mann, G. (1994). Radical Visions: American Film Renaissance, 1967-1976. Westport, Conn.: Greenwood Press.

Nicholls, M. (2004) Scorsese's Men: Melancholia and the Mob. Melbourne: Pluto Press.

Ryan, M. y Kellner, D. (1988). Camera Politica: The Politics and Ideology of Contemporary Hollywood Film. Bloomington: Indiana University Press.

Sherwin, R. K. (2000). When Law Goes Pop. The Vanishing Line Between Law and Popular Culture. Chicago y Londres: The University of Chicago Press.

Stam, R. (2001). Teorías del cine. Barcelona: Paidós Comunicación. Trad. Carles Roche Suárez. [Ed. original: Film Theory, Massachusetts: Blackwell Publishers.]

Thompson, K. (1999). Storytelling in the New Hollywood: Understanding Classical Narrative Technique. Cambridge, Massachusetts: Harvard University Press.

Thompson, K. M. (2007). Apocalyptic Dread. American Film at the Turn of the Millennium. Albany: SUNY press.

Zavala, L. (2005). “Cine clásico, moderno y posmoderno”. En: Razón y Palabra, 46. Disponible en: http://www.razonypalabra.org.mx/anteriores/n46/lzavala.html [fecha de consulta: 23 de enero de 2010]. 